\title{
Glucocorticoids and programming of the microenvironment in heart
}

\author{
Rui Song, Xiang-Qun Hu and Lubo Zhang \\ Lawrence D. Longo, MD Center for Perinatal Biology, Department of Basic Sciences, Loma Linda University School of Medicine, Loma Linda, \\ California, USA
}

Correspondence should be addressed to R Song or L Zhang: rsong01@llu.edu or Izhang@llu.edu

This paper is part of a thematic section on 30 Years of the Developmental Endocrinology of Health and Disease. The guest editors for this section were Sean Limesand, Kent Thornburg and Jane Harding

\begin{abstract}
Glucocorticoids are primary stress hormones and can improve neonatal survival when given to pregnant women threatened by preterm birth or to preterm infants. It has become increasingly apparent that glucocorticoids, primarily by interacting with glucocorticoid receptors, play a critical role in late gestational cardiac maturation. Altered glucocorticoid actions contribute to the development and progression of heart disease. The knowledge gained from studies in the mature heart or cardiac damage is insufficient but a necessary starting point for understanding cardiac programming including programming of the cardiac microenvironment by glucocorticoids in the fetal heart. This review aims to highlight the potential roles of glucocorticoids in programming of the cardiac microenvironment, especially the supporting cells including endothelial cells, immune cells and fibroblasts. The molecular mechanisms by which glucocorticoids regulate the various cellular and extracellular components and the clinical relevance of glucocorticoid functions in the heart are also discussed.
\end{abstract}

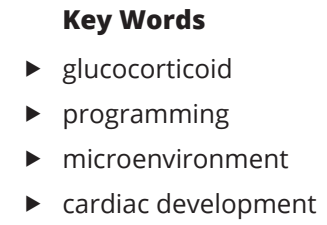

Journal of Endocrinology (2019) 242, T121-T133

\section{Introduction}

Glucocorticoids are a class of corticosteroids and are chiefly produced in the zona fasciculata of the adrenal cortex. These steroid hormones are crucial endocrine regulators of body functions in homeostasis and adaptation to environmental changes. Endogenous glucocorticoids act on a variety of cell types to regulate the expression of genes controlling cellular metabolism, growth, differentiation and apoptosis (Fowden et al. 2004, Grad et al. 2007, Cain et al. 2015). Increasing evidence indicates that glucocorticoids play an essential role in developmental 'programming' of health and disease (Bolt et al. 2001). Glucocorticoids are required for the development of lung, brain, gastrointestinal system, renal system and cardiovascular system. A large number of studies have found that antenatal treatment with exogenous glucocorticoids or exposure to high levels of endogenous glucocorticoids as a result of maternal stress in pregnancy lead to the development of many adult offspring pathologies, including heart disease, stroke, metabolic syndrome and diabetes mellitus (Asztalos 2012, Carson et al. 2016, Kemp et al. 2016, Agnew et al. 2018).

Biological function of glucocorticoids is mainly mediated by binding of these hormones to the cognate intracellular glucocorticoid receptor (GR) encoded by the nuclear receptor subfamily 3 group C member 1 (NR3C1) gene. GR activation could directly induce either gene activation or gene repression and indirectly produce nongenomic effects on gene transcription (Pratt et al. 2006), 
which alters proteins expression and can manifest as maternal stress in pregnancy, illness, inflammation and anxiety. The binding of glucocorticoids to the GR results in receptor homodimerization followed by GR release from the heat shock proteins including heat shock protein 90, heat shock protein 70 and the FK506-binding protein 52 (Pratt et al. 2006). The homodimerized receptor is transported into the nucleus and binds to specific DNAresponsive elements, resulting in the activation of gene transcription. In addition, activated GR can complex with some transcription factors such as NF-kB or AP-1 to prevent them from binding to their target genes, and hence, represses gene expression regulated by these transcription factors (De Bosscher et al. 2014). For nongenomic pathways, glucocorticoid induces rapid signaling events involving phospholipase $\mathrm{C}$, mitogen-activated protein kinases, phosphatidylinositol 3-kinase, Src kinase, $\mathrm{Ca}^{2+} /$ Calmodulin-dependent protein kinase II and synapsin-I, leading to changes in cytoplasmic calcium concentrations, an increase in mitochondrial production of reactive oxygen species, and the lysosomal release of cathepsin B (Sundahl et al. 2015, Ayrout et al. 2017). Both genomic and non-genomic pathways participate in numerous physiological processes required for cell homeostasis and pathophysiological processes mediated by glucocorticoids.

Early insults at critical stages of development may therefore lead to permanent changes in tissue structure and function, a concept now known as programming (Lucas 1991). The programming occurs in the immature, developing myocardium undergoing de novo growth in which a broad and complex array of signals and interactions are surely happening. However, this phenomenon has been sorely understudied. Most research exploring how glucocorticoids regulate function of cardiac cells, including cardiomyocytes and environmental supporting cells, has been primarily conducted in the mature heart, especially the damaged mature heart. Much less is known about the regulation of cardiac cells by glucocorticoids during de novo cardiac development in the fetus or newborn. The knowledge gained from studies in the mature heart or cardiac damage is clearly insufficient to fully understand cardiac programming by glucocorticoids in the fetal heart. However, it is helpful to consider how glucocorticoids regulate cardiac cells in damaged mature heart as a starting point to understand what may be occurring in the fetal heart. In this review, we focus on the role of glucocorticoids in programming of heart development and heart disease. We will discuss mechanisms of epigenetic modifications underlying fetal and adult glucocorticoid programming and potential clinical implications of glucocorticoids based therapeutic approaches for fetal development and cardiovascular disease.

\section{Glucocorticoids in heart development and function}

Endogenous glucocorticoids provide a critical developmental trigger. In a great majority of mammalian species, a surge in levels of maternal glucocorticoids goes into the fetal circulation during late gestation. In sheep, the prepartum surge in cortisol is primarily due to fetal secretion (Challis et al. 2000). This surge is essential for the normal development and the structural and functional maturation of the heart (Fowden et al. 1998, Moisiadis et al. 2014). Mice with targeted GR deletion in cardiomyocytes were born at the expected Mendelian ratio, but died prematurely from spontaneous cardiovascular disease such as spontaneous cardiac hypertrophy, left ventricular dysfunction and heart failure (Oakley et al. 2013). Cortisol administration directly to the near-term fetal lambs increased heart mass that was associated with increased cardiomyocyte proliferation rather than hypertrophy (Giraud et al. 2006). Kim et al. found that developing piglet hearts before the cortisol surge had smaller myocytes with fewer binucleation and more proliferative and fewer apoptotic nuclei than term hearts (Kim et al. 2014). Remarkably, maternal glucocorticoid treatment resulted in increased binucleation with no increase in myocyte volume and levels of proliferation and apoptosis in developing piglet hearts before the cortisol surge (Kim et al. 2014). In addition, there was an increase in the ratio of left to right ventricular weight in female piglet hearts. Furthermore, glucocorticoidinduced myocyte structural maturation is correlated with changes in cardiac function (Eiby et al. 2012, 2013). In an immature baboon model associated with impaired heart function (measured by fractional shortening and velocity of circumferential fiber shortening), a short time course of neonatal hydrocortisone treatment improved cardiac performance including left ventricular function, blood pressure and metabolic acidosis (Yoder et al. 2002), which is consistent with a beneficial effect of glucocorticoids on heart maturation.

Although glucocorticoids are vital for normal fetal development, an exposure to excessive glucocorticoids can reduce fetal growth and has lifelong deleterious effects on the offspring. Prenatal glucocorticoid overexposure is 
associated with permanent hypertension, hyperglycemia and neurobehavioral abnormalities and other consequences to the offspring (Drake et al. 2007). Recent studies have shown that prenatal glucocorticoid excess can cause long-term deleterious cardiometabolic risk and other consequences to the offspring. Dexamethasone overexposure (100-200 $\mu \mathrm{g} / \mathrm{kg} /$ day) in late gestation caused upregulation of $\mathrm{Ca}^{2+}$-binding protein expression in the rat, leading to cardiac impairment and premature death in both the 21-day old fetus and in adulthood, suggesting that elevated maternal glucocorticoids could impair adult cardiac function in offspring (Langdown et al. 2003). Interestingly, prenatal extra glucocorticoid exposure also increased the susceptibility of the myocardium to ischemia/reperfusion injury in adult offspring (Peng et al. 2018). Moreover, this study uncovered the target genes involved in the programming effects of glucocorticoids, and the methylation profile of gene promoters in adult myocardium after prenatal glucocorticoid exposure (Peng et al. 2018). Overall, these observations indicate that fetal exposure to excessive glucocorticoids (either exogenous or endogenous origin) during gestation increases the susceptibility of offspring's heart to 'second strike' which may impair cardiac function in adulthood. Thus, it is strongly evident that glucocorticoids and their receptor are critical for heart maturation and development. Prenatal glucocorticoid exposure either via the mother or directly acting to the fetus substantially programs the physiological heart functions of offspring throughout life.

Cells in the developing embryo are in constant communication with their neighbors, and the molecules they use to send and receive signals are essential for development (Basson 2012). Heart development and function are not only determined by the characteristics of cardiomyocytes, but also critically influenced by their microenvironment. Critical components of the cardiac microenvironment include supporting cells, the extracellular matrix proteins, the mechanical environment of the cells and the soluble components, such as oxygen and cytokines (Mauretti et al. 2017). The heart is a highly organized pluricellular organ consisting of different and equipotent cell types including endothelial cells, immune cells and fibroblasts in addition to cardiomyocytes. Communication among these cell types in a network of structure plays a vital role in the production of the extracellular matrix proteins and the soluble components and response to the mechanical environment of the cells (Bruneau 2013, Mauretti et al. 2017). Therefore, supporting cells in the cardiac microenvironment are crucial for cardiac development, autoregulation and adaptation.
It is possible that besides cardiomyocytes, other cell types are involved in glucocorticoid-mediated heart development and function. It is of interest that mice with either conditional disruption of GR in cardiomyocytes and vascular smooth muscle cells using smooth muscle protein 22-driven Cre recombinase (SMGRKO mice) or global deficiency in $\mathrm{GR}\left(\mathrm{GR}^{-/}\right)$showed altered cardiac ultrastructure with short, disorganized myofibrils in cardiomyocytes at embryonic day (E)17.5 (Rog-Zielinska et al. 2013). Meanwhile, impaired heart function occurred in both SMGRKO and $\mathrm{GR}^{-/-}$mice at E17.5. The impairment of cardiac ultrastructure and function was found to be associated with failure to induce critical genes involved in contractile function, calcium handling and energy metabolism (Rog-Zielinska et al. 2013). Further understanding the programming effects of glucocorticoids on fetal cardiac microenvironment and the role of GR in endothelial cells, macrophages or fibroblasts in the heart development and function would be of great interest in formulating new therapeutic approaches to the treatment of heart disease.

\section{Regulation of glucocorticoids on cardiac microenvironment}

The cardiac microenvironment constitutes a cardiogenic niche that controls cardiac development, function and disease (Atmanli et al. 2017). As mentioned in 'Glucocorticoids in heart development and function' section, supporting cells such as endothelial cells, immune cells and fibroblasts in the cardiac microenvironment are crucial for cardiac development, autoregulation and adaptation. Much less is known about fetal developmental adaptive programming on cardiac supporting cells by glucocorticoids. However, it might be helpful to consider how glucocorticoids regulate cardiac cells in damaged mature heart as a starting point to understand what may be occurring in the fetal heart. In this section, the regulation of supporting cells in the cardiac microenvironment by glucocorticoids and its role in regulation of cardiac function is discussed to speculate the potential effect of glucocorticoids on programming the cardiac microenvironment.

\section{Endothelial cells}

Although during fetal development organ-specific endothelial cells have distinct expression patterns of gene clusters and cell functions, organ-specific endothelial 
cells support host cell survival and function and organ development (Marcu et al. 2018). In cardiac development, endothelial cells may secrete signaling mediators modulating cardiomyocyte development, survival and contraction. Many studies indicate that endothelial cells form an instructive vascular niche to promote organ growth and regeneration through paracrine signaling pathways (Ding et al. 2010, 2011, 2014). In response to physiological or pathological stimuli, endothelial cells can act on the neighboring cell types by secreting angiocrines. Although very little is known about the cardiac EC angiocrines in response to physiological or pathological stimuli, a growing number of EC-derived factors acting on cardiomyocytes have been identified, including nitric oxide (NO), endothelin-1, neuregulin-1, angiotensin II, angiopoietins, prostaglandins, connective tissue growth factor, fibroblast growth factor, vascular endothelial growth factor, Dickkopf-3, apelin and endothelial miRNAs (Segers et al. 2018). It was elucidated that increases in vascular endothelial growth factor A expression in fetal sheep intestines during gestation were strongly associated with fetal circulating glucocorticoids levels (Holmes et al. 2008). However, there was too little known about regulation of glucocorticoids on endothelial cells during cardiac development.

A growing body of literature has demonstrated that the regulation of glucocorticoids/GR on various adult EC-derived factors. The glucocorticoid response element (GRE) is identified in the nitric oxide synthase (eNOS) gene promoter region, which modulates glucocorticoidinduced eNOS suppression in vitro (Liu et al. 2009). Further, the study in EC GR-deficient mice (GR ${ }^{\mathrm{EC}}$ KO) revealed that the expression of eNOS and inducible nitric oxide synthase was increased, leading to NO release in sepsis (Goodwin et al. 2013). In addition, GR agonists dexamethasone and ginsenoside-Rg1 rapidly suppressed the expression of mature miRNA-15b, miRNA-23a and miRNA-214 in human endothelial cells, which may mediate acute cardiovascular protective effects (Kwok et al. 2017). The data form adult endothelial cells could give us some clues for the regulation of glucocorticoids on developing endothelial cells, especially under maternal stress.

Therefore, although the effect of glucocorticoids in the regulation of fetal cardiac endothelial cells activity and function remains largely elusive, it has therapeutic potential to explore the role of glucocorticoids in regulating EC-derived cardiac microenvironment programming in heart development and disease.

\section{Immune cells}

Although our understanding of the human adult immune cells has progressed tremendously, we know very little about the immune cells during fetal development. Recently, the macrophages generated in the heart tube are found to be particularly adept at eating up excess tissue (Shigeta et al. 2019). This makes this endocardial immune cell essential not just to heart valve formation, but to heart valve maintenance throughout life. Because those macrophages remain in the body throughout people's lives, it is important to explore fetal developmental adaptive programming in the immune cells, and it could be possible to target them to treat cardiac disease that develops later in life.

Endogenous and pharmacological glucocorticoids exert robust effects on different immune cells such as macrophages, lymphocytes, B cells and T cells to regulate inflammatory and immune processes. Recently, it has been demonstrated that GR-knockout monocyte-derived macrophages increase pro-inflammatory chemokine CCL5 and decreases interleukin $1 \alpha$ (IL- $1 \alpha$ ), a cytokine that plays a central role in delaying myofibroblast differentiation during the inflammatory phase of healing after ischemic myocardial injury (Galuppo et al. 2017). Blockade of GR inhibited macrophage infiltration and gene expression of monocyte chemoattractant protein-1, osteopontin, cyclooxygenase- 2 and tumor necrosis factor- $\alpha$ (TNF $\alpha$ ) in the left ventricular myocardium, contributing to attenuation of cardiac injury in rats with metabolic syndrome (Takeshita et al. 2015). It is known that IL-10 is a crucial GR target gene in macrophages. IL-10 was recently found to regulate macrophage polarization after myocardial infarction and macrophage bioenergetics during inflammation (Ip et al. 2017, Shirakawa et al. 2018). To date, it is relatively unexplored whether IL-10mediated metabolically reprogramming macrophage to mitophagy plays a role in cardiovascular inflammation. It is likely that glucocorticoids regulate cardiac function at least partly through the action of IL-10 on macrophage phenotype and bioenergetics. It is known that the adult mammalian heart contained specific subsets of both embryonic and adult-derived macrophages at steady state and in response to cardiac stress (Epelman et al. 2014). The knowledge gained from studies in the mature heart or cardiac damage is insufficient, but it is a necessary starting point for understanding cardiac programming by GCs in the fetal heart. Therefore, it is important to further explore effect of glucocorticoid/GR 
signaling on macrophages populations with distinct ontological origins and mechanisms of crosstalk between glucocorticoid/GR signaling and subset-specific pathways in heart development and disorders.

\section{Fibroblasts}

Fibroblast is a prevalent cell type in the cardiac interstitium. Cardiac fibroblasts are generated during embryonic development from the endocardium and epicardium through epithelial-to-mesenchymal transition and lasts until adulthood (Furtado et al. 2016). Disruption of fibroblast activity during embryonic development leads to a heart with smaller ventricular chambers, reduced myocardial thickness or septation defects (Furtado et al. 2016). Physically, fibroblasts can retain the cardiac geometry and function by producing and sustaining the extracellular matrix network in the adult mammalian heart. During disease processes such as myocardial infarction, fibroblasts function in post-infarction inflammation and cardiac repair in the wound microenvironment (Chen et al. 2017). Fibroblast overactivity can cause an imbalance that promotes myocardial hypertrophy and scarring, culminating in heart dilation and impaired function (Furtado et al. 2016). Hydrocortisone at the dose of $127 \mathrm{ng} / \mathrm{mL}$ (equivalent to endogenous basal level of glucocorticoids) inhibited lipopolysaccharide (LPS) $(100 \mathrm{ng} / \mathrm{mL})$-induced productions of TNF $\alpha$ and interleukin $1 \beta$ (IL-1 $\beta$ ) in cardiac fibroblasts, leading to the inhibition of chronic inflammatory disorders during the cardiac disease (Zhang et al. 2017). Corticosteroneinduced collagen synthesis in cultured rat neonatal cardiac fibroblasts under oxidative stress promoted cardiac fibrosis (Omori et al. 2014). Interestingly, in GRLysMCre mice, the inactivation of GR alters the differentiation/maturation of monocyte-derived macrophages in infarcted myocardium, leading to perturbed myofibroblast differentiation after myocardial infarction. It provides in vivo evidence that the macrophage GR regulates myofibroblast differentiation in the infarct microenvironment during the early phase of wound healing (Galuppo et al. 2017). We mainly have data on how adult fibroblasts behave by glucocorticoids, so we have a huge knowledge gap in GC regulation of fibroblasts in the developing fetal heart, which needs to be addressed experimentally.

As cardiac fibroblasts play a prominent role in cardiac development, scarring and regeneration, it is important to explore the role of glucocorticoids in regulating fibroblasts to be reprogrammed into alternative cell lineages and interacting with other cell types in their microenvironment during heart development and disease.

\section{Glucocorticoid signaling and epigenetic mechanism in the heart}

Suboptimal uterine environmental exposure has been linked to short- and long-term cardiovascular disease in adulthood, termed as 'developmental origins of health and disease' (Barker et al. 1988, Vaag et al. 2012, Mandy et al. 2018). Although the exact mechanisms underlying the developmental programming remain largely unclear, emerging studies suggest an important role of epigenetic regulation. Epigenetic mechanisms such as DNA methylation, histone modifications, miRNAs and IncRNAs are relatively stable signals, contributing to developmental origins of health and disease (Chen et al. 2011, Yamada et al. 2017). The genomic and non-genomic mechanisms regulating cardiac gene expression by glucocorticoids during fetal development and postnatal maturation and in disease have been reviewed elsewhere (Pratt et al. 2006, Oakley et al. 2015). Here, we summarize recent progresses in epigenetic regulation of heart development and disease by glucocorticoids.

\section{DNA methylation}

DNA methylation catalyzed by DNA methyltransferases is an epigenetic mechanism for gene regulation (Yang et al. 2010). Dynamic DNA methylation is vital for mammalian heart development and function during numerous developmental processes (e.g., gametogenesis, hematopoiesis stem cell differentiation) and different disease progression (Patterson et al. 2010, Smith et al. 2013, Gilsbach et al. 2014, Martinez et al. 2015). Gay et al. found that 5-aza-2'-deoxycytidine (5-AZA), a global DNA methylation inhibitor, blocked the effects of dexamethasone on binucleation in postnatal day 4 (P4) animals and proliferation at P7, leading to recovered cardiomyocyte number in $\mathrm{P} 14$ hearts. This finding provides evidence that increased DNA methylation mediates glucocorticoids action on inhibiting cardiomyocyte proliferation and stimulating premature terminal cell differentiation in the developing heart (Gay et al. 2015). However, it remains to be elucidated whether and how glucocorticoids regulate DNA methylation via GR. Recently, dexamethasone has been found to downregulate DNA methyltransferases 1 and 3A expression in rat aortic smooth muscle cells, which was blocked by GR antagonist 
mifepristone (Chuang et al. 2017). Further, either inhibition or knockdown of DNA methyltransferases enhanced DEX-mediated miRNA-29c induction (Chuang et al. 2017). Although these findings come from the adult cells, it could provide clues to understand glucocorticoids regulating DNA methylation via GR in heart development and disease.

Perinatal hypoxia and glucocorticoid exposure cause fetal programming during fetal development, leading to an increased risk of adult disease (Zhang 2005). The unliganded GR protein levels can affect its sensitivity to glucocorticoids. Adverse intrauterine environment such as maternal hypoxia can decrease GR protein abundance in rat hearts and this reduction of GR is sustained in the adult offspring (Xue et al. 2011). Our recent study found that maternal hypoxia induced a significant decrease of GR exons $1_{4}, 1_{5}, 1_{6}$ and $1_{7}$ transcripts, leading to downregulation of GR expression in gestational day 21 (E21) rat fetal hearts (Xiong et al. 2016). Hypoxia significantly increased $\mathrm{CpG}$ methylation at the CREs and Sp1-binding sites and decreased transcription factor binding to GR exon 1s promoter, leading to the repression of corresponding GR exons 14-7 mRNA variants and total GR mRNA and protein in the developing heart. Significantly, treatment of newborn pups with DNA methylation inhibitor 5-AZA reversed hypoxia-induced promoter methylation, restored GR expression and prevented hypoxia-mediated increase in ischemia and reperfusion injury of the heart in offspring (Xiong et al. 2016). Our more recent study further established that DNA methylation is a potential mechanistic link between prenatal hypoxia and this epigenetic regulation of GR expression in adult offspring in rats ( $\mathrm{Lv}$ et al. 2019). Thus, our studies provide novel evidence that DNA methylation is an essential epigenetic mechanism in mediating the effect of glucocorticoids not only on the optimal development of the heart but also on heart function after birth. It should be noted that our studies also suggest maternal stress-induced fetal developmental adaptive programming, that is by changing the pattern of developmental (glucocorticoids) signals to the fetus, lasts until adult.

Mata-Greenwood et al. investigated the transcriptional regulation of GR in human umbilical vein endothelial cells (HUVECs) from 25 healthy term pregnancies and demonstrated that dexamethasone-sensitive HUVECs had higher methylation levels of promoter $1 \mathrm{D}$ and lower methylation levels of promoter $1 \mathrm{~F}$ than dexamethasone-resistant HUVECs (Mata-Greenwood et al. 2015). Intriguingly, inhibition of DNA methylation with 5-AZA abolished the differential 5'UTR mRNA isoform expression between dexamethasone-sensitive and dexamethasone-resistant HUVECs. In addition, both GR $\alpha$ overexpression and 5-AZA treatment eliminated the differences between sensitivity groups to dexamethasonemediated downregulation of eNOS and upregulation of plasminogen activator inhibitor 1 (SERPINE1) in HUVECs. These manipulations made the dexamethasoneresistant HUVECs behave like dexamethasone-sensitive HUVECs (Mata-Greenwood et al. 2015). Thus, the study provides novel insights into the upstream mechanisms that alter GR expression in the cardiovascular system and suggests that future use of epigenetic marks would help in identifying glucocorticoid-responsive individuals (Mata-Greenwood et al. 2015).

GRs are activated upon glucocorticoid binding and subsequently interact with their target genes to regulate heart maturation. Intriguingly, adverse intrauterine environment such as maternal hypoxia could regulate GR expression through DNA methylation and consequently modifies glucocorticoids' action in heart development and function. Little attention has been paid to this area and further work is needed to elucidate the role of glucocorticoid signaling in the regulation of DNA methylation in the cardiac microenvironment during heart development and disease.

\section{Histone modifications}

Increasing evidence supports a prominent role of epigenetic histone acetylation modifications in the heart development and cardiovascular defects (Yao et al. 1998, Shikama et al. 2003). The GR lacks deacetylase activity itself. However, it can interact with many of the nuclear corepressor complexes to recruit histone deacetylases.

Knockdown of histone deacetylase (HDAC) 2 reversed hydrocortisone-mediated inhibition of TNF- $\alpha$ and IL-1 $\beta$ production induced by LPS $(100 \mathrm{ng} / \mathrm{mL})$ in cardiac fibroblasts, suggesting that HDAC2 is required for the inhibitory effect of glucocorticoids on the inflammatory response (Zhang et al. 2017). In LPS-stimulated macrophages, GR activation attenuated the recruitment of p300 and histone acetylation, leading to a failure to assemble bromodomain-containing protein 4 coupling the acetylation state with RNA polymerase II elongation and mediator at promoters and enhancers and eventually blocking RNA polymerase II initiation. This histone modification directed GR-driven repression of inflammatory response genes such as $I L-1 a$ and $I L-1 b$ and cluster of differentiation 83 in 
LPS-stimulated macrophages (Sacta et al. 2018). Therefore, histone deacetylation mediates the inhibitory effect of glucocorticoids on the inflammatory response and guides glucocorticoid signaling-driven adaptation in the cardiac microenvironment during cardiovascular development and disease.

\section{miRNAs}

Cardiac development is intricate, involving the differential expression of multiple factors including miRNAs. miRNAs regulate numerous cellular and physiological processes and their dysregulation has been linked to heart disease. The interaction between glucocorticoids and miRNAs is a potential mechanism by which stress selectively modulates gene expression and consequently influences cardiac health. Increasing evidence indicates that miRNAs modulate both glucocorticoid production in the adrenal gland and the responses of various effector cells such as immune cells, osteoblasts, liver cells and spleen cells to glucocorticoids (Clayton et al. 2018). Moreover, glucocorticoids influence cell proliferation, survival and function in part by regulating miRNA expression. It was found that differentially expressed genes between cardiomyopathy patients and healthy donors were enriched for various pathways, of which GR signaling is the most significant. miRNA-30c-5p and miRNA$125 \mathrm{~b}-5 \mathrm{p}$ play an essential role in the regulatory network of differentially expressed genes related to glucocorticoid signaling, which is implicated in cardiomyogenesis or cardiac function (Wang et al. 2014).

A recent study demonstrated that hypoxia induced both HIF-1 $\alpha$-dependent miRNA-210 production and miRNA-210-mediated GR suppression in cardiomyocytes (Martinez et al. 2017). Furthermore, inhibition or knockdown of GR-exacerbated cell death in response to hypoxia-reoxygenation injury, providing novel evidence for a possible mechanistic link between fetal hypoxia and programming of ischemic-sensitive phenotype in the developing heart (Martinez et al. 2017).

miRNAs are also found to mediate GR expression and glucocorticoid downstream signaling in other cell types. Several miRNAs have been implicated in positive or negative regulation of inflammatory responses in immune cells (Sheedy et al. 2008, O'Connell et al. 2010), which may be subject to modulation by glucocorticoids. Recently, RNA pulldown coupled with proteomic analysis recognized that GTPase-activating protein (SH3 domain)-binding protein 1 (G3BP1) mediates
GR-regulated miRNA maturation (Kwok et al. 2017). Activated GR-induced phosphorylation of v-AKT murine thymoma viral oncogene homologue kinase, which in turn phosphorylated and promoted nuclear translocation of G3BP1. The nuclear G3BP1 bound to the G3BP1 consensus sequence located on primary miRNA-15b 16-2 and miR-23a 27a 24-2, leading to impaired maturation and activity of these miRNAs in human endothelial cells (Kwok et al. 2017). Dexamethasone inhibited LPS-induced expression of miRNA-155 in primary macrophages and macrophage cell lines and $\mathrm{T}$ lymphocytes of sepsis patients (Clayton et al. 2018). In short, miRNAs play an essential role in the regulation of GR expression and glucocorticoid signaling in the cardiac supporting cells, which could influence cardiac development and health.

\section{IncRNAs}

Recent studies revealed an important role for lncRNAs in cardiac development, regeneration and cardiovascular disease (Klattenhoff et al. 2013, Michalik et al. 2014, Ounzain et al. 2015). The lncRNA profile in human fetal and adult heart showed that IncRNA ENST00000425771, a 242 nt lncRNA transcribed from the gene growth arrestspecific 5 (GAS5), is located on chromosome 1. GAS5 can act as a riborepressor of the GR by binding to the DNA-binding domain of the GR (Kino et al. 2010). Given glucocorticoids have been demonstrated to be critical for cardiac development (Jaeggi et al. 2004), changes in this lncRNA may contribute to heart development and function.

Several studies demonstrated that IncRNAs are linked to glucocorticoid signaling in endothelial cells, fibroblasts and macrophages. Chowdhury et al. recently demonstrated that EGO, HOTAIRM1 and 1nc-IL7R were markedly increased, which may be associated with a significant increase in GR signaling in human skin microvascular endothelial cells stimulated by LPS (Chowdhury et al. 2017). The gene expression patterns form the basis for functions of endothelial cells including cardiac endothelial cells. IncRNA lethe can be induced by GR agonists to inhibit NF-кB-induced signaling and inflammation in embryonic fibroblasts and macrophages (Rapicavoli et al. 2013, Zgheib et al. 2017).

Taken together, the interplay of glucocorticoids and epigenetic mechanisms plays an essential role in the cardiac microenvironment and consequently influence heart development and disease. However, the mechanisms 
underlying the genetic and epigenetic regulation of gene expression by glucocorticoids during physiological and pathophysiological conditions are still not well understood and merit further investigations.

\section{Clinical implications and future directions}

Over the last decade, significant progresses have been made to advance our understanding of glucocorticoids and their signaling in the programming of heart development and function, which sheds light on the prognosis and management cardiovascular disease (Torres et al. 1997, Abbasi et al. 2000, Liu et al. 2006, 2014, Massari et al. 2012, Gay et al. 2015, Xiong et al. 2016). Glucocorticoid drugs have been commonly used since the 1950s. The synthetic glucocorticoids including betamethasone, budesonide, dexamethasone, hydrocortisone rectal, methylprednisolone, prednisone, prednisolone and triamcinolone are clinically used to treat various pathological conditions such as autoimmune disorders, arthritis, asthma, adrenal insufficiency, cancer, skin conditions and surgery. It is worth noting that short-term use (less than 7 days) of glucocorticoids can help treat heart failure by increasing the body's ability to respond to certain diuretics (Liu et al. 2006, 2014). The 2013 American Heart Association/American College of Cardiology Foundation guidelines currently list 'steroids' among common precipitants of acutely decompensated heart failure (Yancy et al. 2013). Clinically investigating glucocorticoid drugs in the heart development and cardiovascular disease are currently in progress (Zhang et al. 2008, Massari et al. 2012).

Although most clinical trials suggest that sustained exposure or repeated low doses of glucocorticoids prenatally in humans are effective in improving fetal outcomes (Abbasi et al. 2000, Crowther et al. 2006, Asztalos et al. 2010), specific data are lacking in human cardiac development. Glucocorticoid/GR signaling plays an essential role in the maturation of cardiac function shortly before birth, while insufficient or mis-timed glucocorticoid signaling may contribute to common cardiovascular complications. On the other hand, emerging studies have found that prenatal excessive glucocorticoid exposure may delay cardiac maturation, and even cause the pathology for cardiovascular problems in the adult (Torres et al. 1997, Gay et al. 2015, Xiong et al. 2016). However, the time-dependent and concentrationdependent effects of GCs in the fetus are still not fully elucidated in halting the slow development of cardiac dysfunction across the life span. Although the knowledge gained from studies in the mature heart or cardiac damage is clearly insufficient to fully understand cardiac programming by glucocorticoids in the fetal heart, some studies in mature heart provide similar adverse effects of glucocorticoid overexposure as in fetal heart. Sustained excessive glucocorticoid release from the adrenals results in cardiac dysfunction, including myocardial ischemia and hypertrophy and dilated cardiomyopathy (Frustaci et al. 2016). In addition, MacDonald et al. examined medical record data from 68,781 glucocorticoid users and 82,202 nonusers without previous hospitalization for cardiovascular disease. They found that treatment with high-dose glucocorticoids seemed to be associated with an increased risk for cardiovascular disease including heart attack, heart failure and stroke (Wei et al. 2004). So, it is helpful to consider how glucocorticoids regulate cardiac function in damaged mature heart as a starting point to hypothesize understand what may be occurring in the fetal heart. Interestingly, a single dose of glucocorticoids in the presence of small, patchy microembolizationinduced myocardial infarction improved heart function and exerted no adverse effects (Skyschally et al. 2004). Therefore, it is necessary to explore short-term and longterm effects of glucocorticoids on human heart function, as well as programming effects of possible over- or mistimed exposure on the fetal cardiovascular system in greater depth.

There are many aspects of glucocorticoid action that we do not yet know or are just beginning to appreciate, especially in human fetal and adult heart. Clinically, many patients develop resistance to the glucocorticoid treatment, especially in chronic inflammatory disease (Barnes et al. 2009). Attenuated responses to therapeutic glucocorticoid administration can result from three categories: (1) over- or mis-timed exposure of glucocorticoids; (2) genetic (a mutation of GR) causes with the mutant receptors no longer being able to bind hormones and (3) epigenetic causes with homologous downregulation of the functional wild-type receptor. The downregulation of the GR seems to be altered from an epigenetic event to a genetic form of resistance (Silva et al. 1994). Interestingly, the glucocorticoid sensitivity is recently found to be associated with differential methylation at 13 loci in patients with myalgic encephalomyelitis/chronic fatigue syndrome (de Vega et al. 2017). It is thought that modifications to epigenetic loci associated with differences in the glucocorticoid https://joe.bioscientifica.com

https://doi.org/10.1530/JOE-18-0672
(C) 2019 Society for Endocrinology Published by Bioscientifica Ltd. Printed in Great Britain 
sensitivity may be significant as biomarkers of predicting patient steroid responsiveness for future clinical testing, which enables to optimize glucocorticoid therapy.

Moreover, further delineation and dissection of genomic and non-genomic glucocorticoid effects on programming cardiac microenvironment would be necessary for facilitating more specific pharmacological targeting of glucocorticoid effects such that the beneficial effects of glucocorticoid on the heart development and function can be achieved with minimized adverse effects and enhanced glucocorticoid sensitivity.

\section{Conclusion}

The review highlights the significance of glucocorticoids in programming the heart development and function. Epigenetic modifications play an essential role in glucocorticoids-mediated programming in various cellular and extracellular components and the clinical relevance of glucocorticoids function in the heart (Fig. 1). These findings indicate that glucocorticoid signaling is a promising therapeutic target for the development and progression of cardiac disease (Fig. 1).
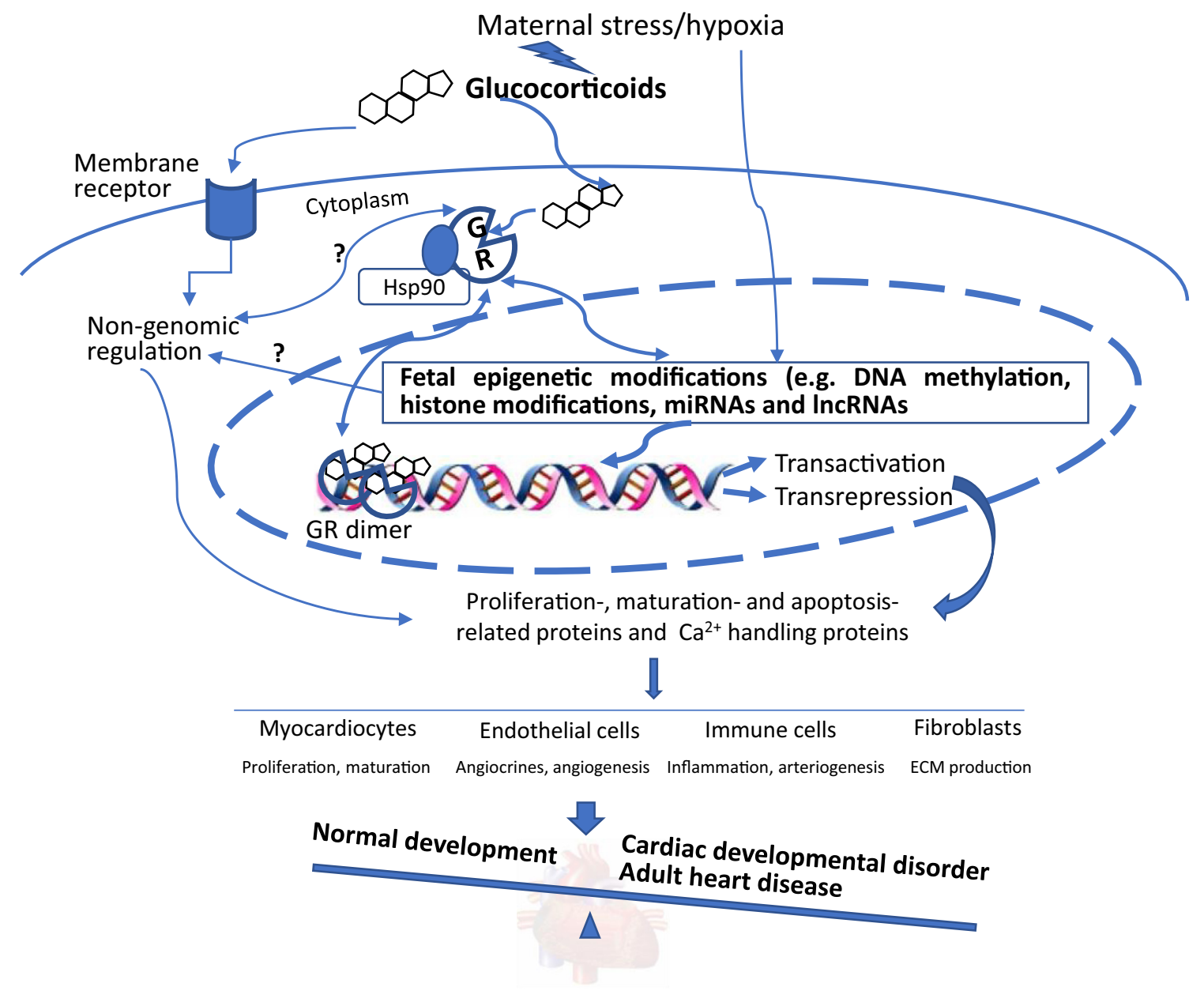

Figure 1

Illustration of the routes by which maternal stress/hypoxia-modified glucocorticoid signaling alters cardiac development and the susceptibility to adult heart disease. Maternal stress/hypoxia induces an excessive release of glucocorticoids which can diffuse across the placenta to enter into the fetal circulation. Activation of the glucocorticoid receptor (GR) by glucocorticoids results in both genomic and non-genomic effects. The glucocorticoid/receptor complex formed in the cytosol could migrate into the nucleus to alter gene expression through transactivation or transrepression (genomic effects). The binding of glucocorticoids to GR in the membrane could activate other cellular signaling pathways (i.e., MAPK, src and PI3K) to elicit rapid responses (non-genomic effects). Maternal stress/hypoxia can also regulate GR expression via epigenetic mechanisms to alter glucocorticoid-induced genomic and non-genomic effects. Moreover, the binding of glucocorticoids to GR in the fetal heart can alter cardiac epigenome (e.g., DNA methylation, histone acetylation, miRNAs and IncRNAs). Together, genomic, non-genomic and epigenetic mechanisms alter fine-tuning proliferation-, maturation- and apoptosis-related proteins and Ca2+ handling proteins, resulting in modification of the activities and functions of cardiomyocytes and supporting cells including endothelial cells, immune cells and fibroblasts in the cardiac microenvironment. Consequently, the cardiac developmental disorder occurs and the susceptibility to heart disease increases in adult offspring. 
We are only beginning to understand the full complexity of this regulation of cardiac microenvironment. The demonstration of the crosstalk between epigenetic mechanisms and other glucocorticoid signaling would open the path to interventions by which glucocorticoid signaling could be manipulated as a potential strategy for the detection and treatment of fetal programming of cardiovascular disease.

\section{Declaration of interest}

The authors declare that there is no conflict of interest that could be perceived as prejudicing the impartiality of this review.

\section{Funding}

This work was supported in part by National Institutes of Health Grants HL118861 (L Z) and HD083132 (L Z).

\section{Author contribution statement}

$\mathrm{R} \mathrm{S}$ drafted the manuscript. $\mathrm{R} \mathrm{S}, \mathrm{X} \mathrm{H}$ and $\mathrm{L} Z$ contributed to revising the manuscript.

\section{References}

Abbasi S, Hirsch D, Davis J, Tolosa J, Stouffer N, Debbs R \& Gerdes JS 2000 Effect of single versus multiple courses of antenatal corticosteroids on maternal and neonatal outcome. American Journal of Obstetrics and Gynecology 182 1243-1249. (https://doi.org/10.1067/ mob.2000.104789)

Agnew EJ, Ivy JR, Stock SJ \& Chapman KE 2018 Glucocorticoids, antenatal corticosteroid therapy and fetal heart maturation. Journal of Molecular Endocrinology 61 R61-R73. (https://doi.org/10.1530/JME18-0077)

Asztalos E 2012 Antenatal corticosteroids: a risk factor for the development of chronic disease. Journal of Nutrition and Metabolism 2012 930591. (https://doi.org/10.1155/2012/930591)

Asztalos EV, Murphy KE, Hannah ME, Willan AR, Matthews SG, Ohlsson A, Kelly EN, Saigal S, Ross S, Delisle MF, et al. 2010 Multiple courses of antenatal corticosteroids for preterm birth study: 2-year outcomes. Pediatrics 126 e1045-e1055. (https://doi.org/10.1542/ peds.2010-0857)

Atmanli A \& Domian IJ 2017 Recreating the cardiac microenvironment in pluripotent stem cell models of human physiology and disease. Trends in Cell Biology 27 352-364. (https://doi.org/10.1016/j.tcb.2016.11.010)

Ayrout M, Simon V, Bernard V, Binart N, Cohen-Tannoudji J, Lombes M \& Chauvin S 2017 A novel non genomic glucocorticoid signaling mediated by a membrane palmitoylated glucocorticoid receptor cross talks with GnRH in gonadotrope cells. Scientific Reports 71537. (https://doi.org/10.1038/s41598-017-01777-2)

Barker DJ \& Osmond C 1988 Low birth weight and hypertension. BMJ 297 134-135.

Barnes PJ \& Adcock IM 2009 Glucocorticoid resistance in inflammatory diseases. Lancet 373 1905-1917. (https://doi.org/10.1016/S01406736(09)60326-3)

Basson MA 2012 Signaling in cell differentiation and morphogenesis. Cold Spring Harbor Perspectives in Biology 4 a008151. (https://doi. org/10.1101/cshperspect.a008151)
Bolt RJ, van Weissenbruch MM, Lafeber HN \& Delemarre-van de Waal HA 2001 Glucocorticoids and lung development in the fetus and preterm infant. Pediatric Pulmonology 32 76-91. (https://doi.org/10.1002/ ppul.1092)

Bruneau BG 2013 Signaling and transcriptional networks in heart development and regeneration. Cold Spring Harbor Perspectives in Biology 5 a008292. (https://doi.org/10.1101/cshperspect.a008292)

Cain DW \& Cidlowski JA 2015 Specificity and sensitivity of glucocorticoid signaling in health and disease. Best Practice and Research: Clinical Endocrinology and Metabolism 29 545-556. (https:// doi.org/10.1016/j.beem.2015.04.007)

Carson R, Monaghan-Nichols AP, DeFranco DB \& Rudine AC 2016 Effects of antenatal glucocorticoids on the developing brain. Steroids $\mathbf{1 1 4}$ 25-32. (https://doi.org/10.1016/j.steroids.2016.05.012)

Challis JRG, Matthews SG, Gibb W \& Lye SJ 2000 Endocrine and paracrine regulation of birth at term and preterm. Endocrine Reviews 21 514-550. (https://doi.org/10.1210/edrv.21.5.0407)

Chen B \& Frangogiannis NG 2017 Immune cells in repair of the infarcted myocardium. Microcirculation 24 e12305. (https://doi.org/10.1111/ micc.12305)

Chen M \& Zhang L 2011 Epigenetic mechanisms in developmental programming of adult disease. Drug Discovery Today 16 1007-1018. (https://doi.org/10.1016/j.drudis.2011.09.008)

Chowdhury IH, Narra HP, Sahni A, Khanipov K, Schroeder CLC, Patel J, Fofanov Y \& Sahni SK 2017 Expression profiling of long noncoding RNA splice variants in human microvascular endothelial cells: lipopolysaccharide effects in vitro. Mediators of Inflammation 2017 3427461. (https://doi.org/10.1155/2017/3427461)

Chuang TD \& Khorram O 2017 Glucocorticoids regulate miR-29c levels in vascular smooth muscle cells through transcriptional and epigenetic mechanisms. Life Sciences 186 87-91. (https://doi. org/10.1016/j.lfs.2017.08.007)

Clayton SA, Jones SW, Kurowska-Stolarska M \& Clark AR 2018 The role of microRNAs in glucocorticoid action. Journal of Biological Chemistry 293 1865-1874. (https://doi.org/10.1074/jbc.R117.000366)

Crowther CA, Haslam RR, Hiller JE, Doyle LW, Robinson JS \& Australasian Collaborative Trial of Repeat Doses of Steroids (ACTORDS) Study Group 2006 Neonatal respiratory distress syndrome after repeat exposure to antenatal corticosteroids: a randomised controlled trial. Lancet 367 1913-1919. (https://doi.org/10.1016/S0140-6736(06)68846-6)

De Bosscher K, Beck IM, Dejager L, Bougarne N, Gaigneaux A, Chateauvieux S, Ratman D, Bracke M, Tavernier J, Vanden Berghe W, et al. 2014 Selective modulation of the glucocorticoid receptor can distinguish between transrepression of NF-kappaB and AP-1. Cellular and Molecular Life Sciences 71 143-163. (https://doi.org/10.1007/ s00018-013-1367-4)

de Vega WC, Herrera S, Vernon SD \& McGowan PO 2017 Epigenetic modifications and glucocorticoid sensitivity in myalgic encephalomyelitis/chronic fatigue syndrome (ME/CFS). BMC Medical Genomics 10 11. (https://doi.org/10.1186/s12920-017-0248-3)

Ding BS, Nolan DJ, Butler JM, James D, Babazadeh AO, Rosenwaks Z, Mittal V, Kobayashi H, Shido K, Lyden D, et al. 2010 Inductive angiocrine signals from sinusoidal endothelium are required for liver regeneration. Nature 468 310-315. (https://doi.org/10.1038/nature09493)

Ding BS, Nolan DJ, Guo P, Babazadeh AO, Cao Z, Rosenwaks Z, Crystal RG, Simons M, Sato TN, Worgall S, et al. 2011 Endothelialderived angiocrine signals induce and sustain regenerative lung alveolarization. Cell 147 539-553. (https://doi.org/10.1016/j. cell.2011.10.003)

Ding BS, Cao Z, Lis R, Nolan DJ, Guo P, Simons M, Penfold ME, Shido K, Rabbany SY \& Rafii S 2014 Divergent angiocrine signals from vascular niche balance liver regeneration and fibrosis. Nature 505 97-102. (https://doi.org/10.1038/nature12681)

Drake AJ, Tang JI \& Nyirenda MJ 2007 Mechanisms underlying the role of glucocorticoids in the early life programming of adult disease. Clinical Science 113 219-232. (https://doi.org/10.1042/CS20070107) 
Eiby YA, Lumbers ER, Headrick JP \& Lingwood BE 2012 Left ventricular output and aortic blood flow in response to changes in preload and afterload in the preterm piglet heart. American Journal of Physiology: Regulatory, Integrative and Comparative Physiology 303 R769-R777. (https://doi.org/10.1152/ajpregu.00010.2012)

Eiby YA, Wright LL, Kalanjati VP, Miller SM, Bjorkman ST, Keates HL, Lumbers ER, Colditz PB \& Lingwood BE 2013 A pig model of the preterm neonate: anthropometric and physiological characteristics. PLOS ONE 8 e68763. (https://doi.org/10.1371/journal.pone.0068763)

Epelman S, Lavine KJ, Beaudin AE, Sojka DK, Carrero JA, Calderon B, Brija T, Gautier EL, Ivanov S, Satpathy AT, et al. 2014 Embryonic and adult-derived resident cardiac macrophages are maintained through distinct mechanisms at steady state and during inflammation. Immunity 40 91-104. (https://doi.org/10.1016/j.immuni.2013.11.019)

Fowden AL \& Forhead AJ 2004 Endocrine mechanisms of intrauterine programming. Reproduction 127 515-526. (https://doi.org/10.1530/ rep.1.00033)

Fowden AL, Li J \& Forhead AJ 1998 Glucocorticoids and the preparation for life after birth: are there long-term consequences of the life insurance? Proceedings of the Nutrition Society 57 113-122. (https://doi org/10.1079/PNS19980017)

Frustaci A, Letizia C, Verardo R, Grande C, Petramala L, Russo MA \& Chimenti C 2016 Cushing syndrome cardiomyopathy: clinicopathologic impact of cortisol normalization. Circulation: Cardiovascular Imaging 9 e004569. (https://doi.org/10.1161/ CIRCIMAGING.116.004569)

Furtado MB, Nim HT, Boyd SE \& Rosenthal NA 2016 View from the heart: cardiac fibroblasts in development, scarring and regeneration. Development 143 387-397. (https://doi.org/10.1242/dev.120576)

Galuppo P, Vettorazzi S, Hovelmann J, Scholz CJ, Tuckermann JP, Bauersachs J \& Fraccarollo D 2017 The glucocorticoid receptor in monocyte-derived macrophages is critical for cardiac infarct repair and remodeling. FASEB Journal 31 5122-5132. (https://doi. $\operatorname{org} / 10.1096 /$ fj.201700317R)

Gay MS, Li Y, Xiong F, Lin T \& Zhang L 2015 Dexamethasone treatment of newborn rats decreases cardiomyocyte endowment in the developing heart through epigenetic modifications. PLOS ONE 10 e0125033. (https://doi.org/10.1371/journal.pone.0125033)

Gilsbach R, Preissl S, Gruning BA, Schnick T, Burger L, Benes V, Wurch A, Bonisch U, Gunther S, Backofen R, et al. 2014 Dynamic DNA methylation orchestrates cardiomyocyte development, maturation and disease. Nature Communications 5 5288. (https://doi.org/10.1038/ ncomms6288)

Giraud GD, Louey S, Jonker S, Schultz J \& Thornburg KL 2006 Cortisol stimulates cell cycle activity in the cardiomyocyte of the sheep fetus. Endocrinology 147 3643-3649. (https://doi.org/10.1210/en.2006-0061)

Goodwin JE, Feng Y, Velazquez H \& Sessa WC 2013 Endothelial glucocorticoid receptor is required for protection against sepsis. PNAS 110 306-311. (https://doi.org/10.1073/pnas.1210200110)

Grad I \& Picard D 2007 The glucocorticoid responses are shaped by molecular chaperones. Molecular and Cellular Endocrinology 275 2-12. (https://doi.org/10.1016/j.mce.2007.05.018)

Holmes K, Charnock Jones SD, Forhead AJ, Giussani DA, Fowden AL, Licence D, Kempster S \& Smith GC 2008 Localization and control of expression of VEGF-A and the VEGFR-2 receptor in fetal sheep intestines. Pediatric Research 63 143-148. (https://doi.org/10.1203/ PDR.0b013e31815f00e0)

Ip WKE, Hoshi N, Shouval DS, Snapper S \& Medzhitov R 2017 Antiinflammatory effect of IL-10 mediated by metabolic reprogramming of macrophages. Science 356 513-519. (https://doi.org/10.1126/ science.aal3535)

Jaeggi ET, Fouron JC, Silverman ED, Ryan G, Smallhorn J \& Hornberger LK 2004 Transplacental fetal treatment improves the outcome of prenatally diagnosed complete atrioventricular block without structural heart disease. Circulation 110 1542-1548. (https:// doi.org/10.1161/01.CIR.0000142046.58632.3A)
Kemp MW, Newnham JP, Challis JG, Jobe AH \& Stock SJ 2016 The clinical use of corticosteroids in pregnancy. Human Reproduction Update 22 240-259. (https://doi.org/10.1093/humupd/dmv047)

Kim MY, Eiby YA, Lumbers ER, Wright LL, Gibson KJ, Barnett AC \& Lingwood BE 2014 Effects of glucocorticoid exposure on growth and structural maturation of the heart of the preterm piglet. PLOS ONE 9 e93407. (https://doi.org/10.1371/journal.pone.0093407)

Kino T, Hurt DE, Ichijo T, Nader N \& Chrousos GP 2010 Noncoding RNA gas 5 is a growth arrest- and starvation-associated repressor of the glucocorticoid receptor. Science Signaling 3 ra8. (https://doi. org/10.1126/scisignal.2000568)

Klattenhoff CA, Scheuermann JC, Surface LE, Bradley RK, Fields PA, Steinhauser ML, Ding H, Butty VL, Torrey L, Haas S, et al. 2013 Braveheart, a long noncoding RNA required for cardiovascular lineage commitment. Cell 152 570-583. (https://doi.org/10.1016/j. cell.2013.01.003)

Kwok HH, Poon PY, Mak KH, Zhang LY, Liu P, Zhang H, Mak NK, Yue PY \& Wong RN 2017 Role of G3BP1 in glucocorticoid receptor-mediated microRNA-15b and microRNA-23a biogenesis in endothelial cells. Cellular and Molecular Life Sciences 74 3613-3630. (https://doi. org/10.1007/s00018-017-2540-y)

Langdown ML, Holness MJ \& Sugden MC 2003 Effects of prenatal glucocorticoid exposure on cardiac calreticulin and calsequestrin protein expression during early development and in adulthood. Biochemical Journal 371 61-69. (https://doi.org/10.1042/BJ20021771)

Liu C \& Liu K 2014 Effects of glucocorticoids in potentiating diuresis in heart failure patients with diuretic resistance. Journal of Cardiac Failure 20 625-629. (https://doi.org/10.1016/j.cardfail.2014.06.353)

Liu C, Chen H, Zhou C, Ji Z, Liu G, Gao Y, Tian L, Yao L, Zheng Y, Zhao Q, et al. 2006 Potent potentiating diuretic effects of prednisone in congestive heart failure. Journal of Cardiovascular Pharmacology $\mathbf{4 8}$ 173-176. (https://doi.org/10.1097/01.fjc.0000245242.57088.5b)

Liu Y, Mladinov D, Pietrusz JL, Usa K \& Liang M 2009 Glucocorticoid response elements and 11 beta-hydroxysteroid dehydrogenases in the regulation of endothelial nitric oxide synthase expression. Cardiovascular Research 81 140-147. (https://doi.org/10.1093/cvr/ cvn231)

Lucas A 1991 Programming by early nutrition in man. Ciba Foundation Symposium 156 38-50; discussion 50-55. (https://doi. org/10.1002/9780470514047.ch4)

Lv J, Ma Q, Dasgupta C, Xu Z \& Zhang L 2019 Antenatal hypoxia and programming of glucocorticoid receptor expression in the adult rat heart. Frontiers in Physiology 10 323. (https://doi.org/10.3389/ fphys.2019.00323)

Mandy M \& Nyirenda M 2018 Developmental origins of health and disease: the relevance to developing nations. International Health 10 66-70. (https://doi.org/10.1093/inthealth/ihy006)

Marcu R, Choi YJ, Xue J, Fortin CL, Wang Y, Nagao RJ, Xu J, MacDonald JW, Bammler TK, Murry CE, et al. 2018 Human organspecific endothelial cell heterogeneity. iScience 4 20-35. (https://doi. org/10.1016/j.isci.2018.05.003)

Martinez SR, Gay MS \& Zhang L 2015 Epigenetic mechanisms in heart development and disease. Drug Discovery Today 20 799-811. (https:// doi.org/10.1016/j.drudis.2014.12.018)

Martinez SR, Ma Q, Dasgupta C, Meng X \& Zhang L 2017 MicroRNA-210 suppresses glucocorticoid receptor expression in response to hypoxia in fetal rat cardiomyocytes. Oncotarget 8 80249-80264. (https://doi. org/10.18632/oncotarget.17801)

Massari F, Mastropasqua F, Iacoviello M, Nuzzolese V, Torres D \& Parrinello G 2012 The glucocorticoid in acute decompensated heart failure: Dr Jekyll or Mr Hyde? American Journal of Emergency Medicine 30 517.e5-517.e10. (https://doi.org/10.1016/j.ajem.2011.01.023)

Mata-Greenwood E, Jackson PN, Pearce WJ \& Zhang L 2015 Endothelial glucocorticoid receptor promoter methylation according to dexamethasone sensitivity. Journal of Molecular Endocrinology 55 133-146. (https://doi.org/10.1530/JME-15-0124) 
Mauretti A, Spaans S, Bax NAM, Sahlgren C \& Bouten CVC 2017 Cardiac progenitor cells and the interplay with their microenvironment. Stem Cells International 2017 7471582. (https:// doi.org/10.1155/2017/7471582)

Michalik KM, You X, Manavski Y, Doddaballapur A, Zornig M, Braun T, John D, Ponomareva Y, Chen W, Uchida S, et al. 2014 Long noncoding RNA MALAT1 regulates endothelial cell function and vessel growth. Circulation Research 114 1389-1397. (https://doi. org/10.1161/CIRCRESAHA.114.303265)

Moisiadis VG \& Matthews SG 2014 Glucocorticoids and fetal programming part 1: outcomes. Nature Reviews: Endocrinology 10 391-402. (https://doi.org/10.1038/nrendo.2014.73)

Oakley RH \& Cidlowski JA 2015 Glucocorticoid signaling in the heart: a cardiomyocyte perspective. Journal of Steroid Biochemistry and Molecular Biology 153 27-34. (https://doi.org/10.1016/j.jsbmb.2015.03.009)

Oakley RH, Ren R, Cruz-Topete D, Bird GS, Myers PH, Boyle MC, Schneider MD, Willis MS \& Cidlowski JA 2013 Essential role of stress hormone signaling in cardiomyocytes for the prevention of heart disease. PNAS 110 17035-17040. (https://doi.org/10.1073/ pnas.1302546110)

O'Connell RM, Rao DS, Chaudhuri AA \& Baltimore D 2010 Physiological and pathological roles for microRNAs in the immune system. Nature Reviews: Immunology 10 111-122. (https://doi.org/10.1038/nri2708)

Omori Y, Mano T, Ohtani T, Sakata Y, Takeda Y, Tamaki S, Tsukamoto Y, Miwa T, Yamamoto K \& Komuro I 2014 Glucocorticoids induce cardiac fibrosis via mineralocorticoid receptor in oxidative stress: contribution of elongation factor eleven-nineteen lysine-rich leukemia (ELL). Yonago Acta Medica 57 109-116.

Ounzain S, Micheletti R, Beckmann T, Schroen B, Alexanian M, Pezzuto I, Crippa S, Nemir M, Sarre A, Johnson R, et al. 2015 Genome-wide profiling of the cardiac transcriptome after myocardial infarction identifies novel heart-specific long non-coding RNAs. European Heart Journal 36 353a-368a. (https://doi.org/10.1093/eurheartj/ehu180)

Patterson AJ, Chen M, Xue Q, Xiao D \& Zhang L 2010 Chronic prenatal hypoxia induces epigenetic programming of PKC\{epsilon\} gene repression in rat hearts. Circulation Research 107 365-373. (https://doi. org/10.1161/CIRCRESAHA.110.221259)

Peng J, Zhou Y, Zhang Z, Wang Z, Gao L, Zhang X, Fang Z, Li G, Chen H, Yang H, et al. 2018 The detrimental effects of glucocorticoids exposure during pregnancy on offspring's cardiac functions mediated by hypermethylation of bone morphogenetic protein-4. Cell Death and Disease 9 834. (https://doi.org/10.1038/s41419-018-0841-1)

Pratt WB, Morishima Y, Murphy M \& Harrell M 2006 Chaperoning of glucocorticoid receptors. Handbook of Experimental Pharmacology 172 111-138. (https://doi.org/10.1007/3-540-29717-0_5)

Rapicavoli NA, Qu K, Zhang J, Mikhail M, Laberge RM \& Chang HY 2013 A mammalian pseudogene IncRNA at the interface of inflammation and anti-inflammatory therapeutics. eLife 2 e00762. (https://doi. org/10.7554/eLife.00762)

Rog-Zielinska EA, Thomson A, Kenyon CJ, Brownstein DG, Moran CM, Szumska D, Michailidou Z, Richardson J, Owen E, Watt A, et al. 2013 Glucocorticoid receptor is required for foetal heart maturation. Human Molecular Genetics 22 3269-3282. (https://doi.org/10.1093/ hmg/ddt182)

Sacta MA, Tharmalingam B, Coppo M, Rollins DA, Deochand DK, Benjamin B, Yu L, Zhang B, Hu X, Li R, et al. 2018 Gene-specific mechanisms direct glucocorticoid-receptor-driven repression of inflammatory response genes in macrophages. eLife $\mathbf{7}$ e34864. (https://doi.org/10.7554/eLife.34864)

Segers VFM, Brutsaert DL \& De Keulenaer GW 2018 Cardiac remodeling: endothelial cells have more to say than just no. Frontiers in Physiology 9 382. (https://doi.org/10.3389/fphys.2018.00382)

Sheedy FJ \& O'Neill LA 2008 Adding fuel to fire: microRNAs as a new class of mediators of inflammation. Annals of the Rheumatic Diseases $\mathbf{6 7}$ (Supplement 3) iii50-iii55. (https://doi.org/10.1136/ard.2008.100289)
Shigeta A, Huang V, Zuo J, Besada R, Nakashima Y, Lu Y, Ding Y, Pellegrini M, Kulkarni RP, Hsiai T, et al. 2019 Endocardially derived macrophages are essential for valvular remodeling. Developmental Cell 48 617.e3-630.e3. (https://doi.org/10.1016/j.devcel.2019.01.021)

Shikama N, Lutz W, Kretzschmar R, Sauter N, Roth JF, Marino S, Wittwer J, Scheidweiler A \& Eckner R 2003 Essential function of p300 acetyltransferase activity in heart, lung and small intestine formation. EMBO Journal 22 5175-5185. (https://doi.org/10.1093/ emboj/cdg502)

Shirakawa K, Endo J, Kataoka M, Katsumata Y, Yoshida N, Yamamoto T, Isobe S, Moriyama $\mathrm{H}$, Goto S, Kitakata $\mathrm{H}$, et al. $2018 \mathrm{IL}$ (interleukin)-10-STAT3-galectin-3 axis is essential for osteopontinproducing reparative macrophage polarization After myocardial infarction. Circulation 138 2021-2035. (https://doi.org/10.1161/ CIRCULATIONAHA.118.035047)

Silva CM, Powell-Oliver FE, Jewell CM, Sar M, Allgood VE \& Cidlowski JA 1994 Regulation of the human glucocorticoid receptor by long-term and chronic treatment with glucocorticoid. Steroids 59 436-442. (https://doi.org/10.1016/0039-128X(94)90013-2)

Skyschally A, Haude M, Dorge H, Thielmann M, Duschin A, van de Sand A, Konietzka I, Buchert A, Aker S, Massoudy P, et al. 2004 Glucocorticoid treatment prevents progressive myocardial dysfunction resulting from experimental coronary microembolization. Circulation 109 2337-2342. (https://doi. org/10.1161/01.CIR.0000127961.66744.F4)

Smith ZD \& Meissner A 2013 DNA methylation: roles in mammalian development. Nature Reviews: Genetics 14 204-220. (https://doi. org/10.1038/nrg3354)

Sundahl N, Bridelance J, Libert C, De Bosscher K \& Beck IM 2015 Selective glucocorticoid receptor modulation: new directions with non-steroidal scaffolds. Pharmacology and Therapeutics 152 28-41. (https://doi.org/10.1016/j.pharmthera.2015.05.001)

Takeshita Y, Watanabe S, Hattori T, Nagasawa K, Matsuura N, Takahashi K, Murohara T \& Nagata K 2015 Blockade of glucocorticoid receptors with RU486 attenuates cardiac damage and adipose tissue inflammation in a rat model of metabolic syndrome. Hypertension Research 38 741-750. (https://doi.org/10.1038/hr.2015.77)

Torres A, Belser WW 3rd, Umeda PK \& Tucker D 1997 Indicators of delayed maturation of rat heart treated prenatally with dexamethasone. Pediatric Research 42 139-144. (https://doi. org/10.1203/00006450-199708000-00001)

Vaag AA, Grunnet LG, Arora GP \& Brons C 2012 The thrifty phenotype hypothesis revisited. Diabetologia 55 2085-2088. (https://doi. org/10.1007/s00125-012-2589-y)

Wang L, Hu J, Xing H, Sun M, Wang J, Jian Q \& Yang H 2014 Construction of microRNA and transcription factor regulatory network based on gene expression data in cardiomyopathy. European Journal of Medical Research 19 57. (https://doi.org/10.1186/s40001014-0057-5)

Wei L, MacDonald TM \& Walker BR 2004 Taking glucocorticoids by prescription is associated with subsequent cardiovascular disease. Annals of Internal Medicine 141 764-770. (https://doi org/10.7326/0003-4819-141-10-200411160-00007)

Xiong F, Lin T, Song M, Ma Q, Martinez SR, Lv J, MataGreenwood E, Xiao D, Xu Z \& Zhang L 2016 Antenatal hypoxia induces epigenetic repression of glucocorticoid receptor and promotes ischemicsensitive phenotype in the developing heart. Journal of Molecular and Cellular Cardiology 91 160-171. (https://doi.org/10.1016/j. yjmcc.2016.01.003)

Xue Q, Dasgupta C, Chen M \& Zhang L 2011 Foetal hypoxia increases cardiac AT(2)R expression and subsequent vulnerability to adult ischaemic injury. Cardiovascular Research 89 300-308. (https://doi. org $/ 10.1093 / \mathrm{cvr} / \mathrm{cvq} 303)$

Yamada L \& Chong S 2017 Epigenetic studies in developmental origins of health and disease: pitfalls and key considerations for study design https://joe.bioscientifica.com

https://doi.org/10.1530/JOE-18-0672 (c) 2019 Society for Endocrinology Published by Bioscientifica Ltd. Printed in Great Britain 
and interpretation. Journal of Developmental Origins of Health and Disease 8 30-43. (https://doi.org/10.1017/S2040174416000507)

Yancy CW, Jessup M, Bozkurt B, Butler J, Casey DE Jr, Drazner MH, Fonarow GC, Geraci SA, Horwich T, Januzzi JL, et al. 20132013 ACCF/ AHA guideline for the management of heart failure: a report of the American College of Cardiology Foundation/American Heart Association Task Force on practice guidelines. Journal of the American College of Cardiology 62 e147-e239. (https://doi.org/10.1016/j.jacc.2013.05.019)

Yang X, Lay F, Han H \& Jones PA 2010 Targeting DNA methylation for epigenetic therapy. Trends in Pharmacological Sciences 31 536-546. (https://doi.org/10.1016/j.tips.2010.08.001)

Yao TP, Oh SP, Fuchs M, Zhou ND, Ch'ng LE, Newsome D, Bronson RT, Li E, Livingston DM \& Eckner R 1998 Gene dosage-dependent embryonic development and proliferation defects in mice lacking the transcriptional integrator p300. Cell 93 361-372. (https://doi. org/10.1016/S0092-8674(00)81165-4)

Yoder B, Martin H, McCurnin DC \& Coalson JJ 2002 Impaired urinary cortisol excretion and early cardiopulmonary dysfunction in immature baboons. Pediatric Research 51 426-432. (https://doi. org/10.1203/00006450-200204000-00006)

Zgheib C, Hodges MM, Hu J, Liechty KW \& Xu J 2017 Long non-coding RNA Lethe regulates hyperglycemia-induced reactive oxygen species production in macrophages. PLOS ONE 12 e0177453. (https://doi. org/10.1371/journal.pone.0177453)

Zhang L 2005 Prenatal hypoxia and cardiac programming. Journal of the Society for Gynecologic Investigation 12 2-13. (https://doi.org/10.1016/j. jsgi.2004.09.004)

Zhang H, Liu C, Ji Z, Liu G, Zhao Q, Ao YG, Wang L, Deng B, Zhen Y, Tian L, et al. 2008 Prednisone adding to usual care treatment for refractory decompensated congestive heart failure. International Heart Journal 49 587-595. (https://doi.org/10.1536/ihj.49.587)

Zhang H, He Y, Zhang G, Li X, Yan S, Hou N, Xiao Q, Huang Y, Luo M, Zhang G, et al. 2017 HDAC2 is required by the physiological concentration of glucocorticoid to inhibit inflammation in cardiac fibroblasts. Canadian Journal of Physiology and Pharmacology 95 1030-1038. (https://doi.org/10.1139/cjpp-2016-0449)

Received in final form 8 April 2019

Accepted 24 April 2019

Accepted Preprint published online 24 April 2019 (c) 2019 Society for Endocrinology Published by Bioscientifica Ltd. 